\title{
Mitochondrial tRNA mutations in Chinese Hypertensive
}

\section{Individuals}

Yuqi Liu ${ }^{1 \mathrm{a}}$, Yang $\mathrm{Li}^{1 \mathrm{a}}$, Xin Wang ${ }^{2 \mathrm{a}}$, Qinha $\mathrm{Ma}^{3 \mathrm{a}}$, Chao Zhu ${ }^{1}$, Zongbin $\mathrm{Li}^{1}$, Tong Yin $^{1}$,

Jie Yang ${ }^{1}$, Yundai Chen ${ }^{1 *}$, Minxin Guan ${ }^{4,5,6^{*}}$.

${ }^{1}$ Department of Cardiology, Chinese PLA General Hospital, Beijing, China

${ }^{2}$ Department of Health Statisitcs, Fourth Military Medical University, Chinese PLA Police Force Center for Disease Control and Prevention, Xi'an, Shanxi Province, China

${ }^{3}$ Department of cardiology, Yishui Center hospital of Shandong Province, Linyi, China.

${ }^{4}$ Institute of Genetics, College of Life Sciences, Zhejiang University, Hangzhou, Zhejiang, China

${ }^{5}$ Division of Human Genetics, Cincinnati Children's Hospital Medical Center, Cincinnati, Ohio, USA

${ }^{6}$ Division of Pathology, Cincinnati Children's Hospital Medical Center, Cincinnati, Ohio, USA

\section{*Corresponding author:}

Min-Xin Guan, Ph.D, Institute of Genetics, Zhejiang University, Hangzhou, Zhejiang 310058, China, E-mail: gminxin88@zju.edu.cn; Telephone: (571) 8820-6485; FAX: (571) 8820-8569; Yundai Chen, MD, Department of Cardiology, Chinese PLA General Hospital,beijing, 100853,China, E-mail:cyundai@vip.163.com

${ }^{a}$ contributed equally to this work.

\section{ABSTRACT}


Purpose: Hypertension is a very important risk factor for cardiac vascular disease. The previous studies showed that mitochondrial DNA mutations are associated with cardiovascular disease, including hypertension.

Methods: In this study we did systematical analysis on the total 22 mitochondrial tRNAs and the clinical, genetic and molecular changes of 140 Chinese hypertension and 124 controls.

Results: This analysis identified 22 nucleotide changes among 15 different tRNA genes. There are 15 mutations with CI (Conservation index) larger than $75 \%$. Of these, there are 26 patients with CI larger than $75 \%$ in the HTN group, higher than the 6 subjects in the control group $(P=0.00)$. The tRNA ${ }^{\text {Phe }}$ G586A, tRNA ${ }^{\text {Lys }}$ G8313A and tRNA $^{\text {His }}$ G12147A mutations create highly conservative base-pairings on the D-stem, tRNA $^{\text {Lys }}$ G8342A on the T-stem, tRNA ${ }^{\text {Phe }}$ T616C, tRNA ${ }^{\text {Ala }}$ T5628C, tRNA ${ }^{\text {Tyr }}$ G5856A and $\mathrm{tRNA}^{\mathrm{Thr}} \mathrm{A} 15924 \mathrm{G}$ on the AC stem, tRNA ${ }^{\mathrm{Leu}(\mathrm{CUN})} \mathrm{G} 12300 \mathrm{~A}$ on the AC loop, tRNA ${ }^{\text {Met }}$ C4467T, tRNA ${ }^{\text {Trp }}$ T5578C, tRNA ${ }^{\text {Lys }}$ A8296G, tRNA Arg T10463C and tRNA $^{\text {Thr }}$ C15891T on ACC stem, and tRNA ${ }^{\text {Ser(UCN) }}$ C7492T on D-A junction, while the other tRNA variants were polymorphisms. The pedigrees of $\mathrm{PLAH}_{78}$ carrying the T5578C, $\mathrm{PLAH}_{84}$ carrying the C4467T, $\mathrm{PLAH}_{60}$ carrying the T5628C and $\mathrm{PLAH}_{118}$ carrying the C7492T mutation exhibited maternal transmission of essential hypertension. Sequence analysis of their mitochondrial genomes revealed the presence of T5578C, C4467T, T5628C or C7492T mutations but the absence of other functionally significant mutations in all matrilineal relatives of these families.

Conclusions: These tRNAs mutations, associated with altered structures of tRNAs 
and mitochondrial dysfunction, may contribute to the hypertension in Chinese population. A lot of work still should be done for the mechanism and functional effect of the mtDNA mutation on hypertension.

Key words: Hypertension; maternal transmission; mitochondrial tRNAs; mutation

\section{Introduction}


Hypertension (HTN) is a major public health problem, affecting approximately 1 billion worldwide. [Guidelines Subcommittee, 1999] Hypertension is also a major risk factor for coronary heart disease, stroke, congestive heart failure and renal disease. [Chobanian, et al., 2003] Currently essential hypertension (EH) are regarded as a multifactorial disease, and the onset and severity of which are influenced by both genetic and environmental factors. The role of genetic factors in the etiology of hypertension is supported by cross-sectional studies that document familial aggregation of the disorder despite different environmental factors. [Zinner, et al., 1971; Havlik, et al., 1982] Estimates of genetic variance range from $20 \%$ to $50 \%$.[ Rice, et al., 1989; Longini, et al., 1984; Hunt, et al., 1989] Significant blood pressure (BP) correlations between mothers and offspring or excess maternal transmission of hypertension have been noted in several early[Bengtsson, et al., 1979] and more recent[DeStefano, et al., 2001] investigations, whereas such correlations between fathers and offspring were either marginal or absent in these studies. Our previous studies reported a finding of excess maternal transmission of HTN in hypertensive families. [Liu, et al.,2008; Li, et al.,2007; Liu, et al., 2009;Li, et al., 2009; Shiwen, et al., 2011 ] By far the most widely studied class of mtDNA point mutations are those affecting single tRNA genes. At the present time, mutations in 19 of the 22 human mitochondrial tRNA gene have been reported in association with disease, although not every one has been validated by mechanistic studiedies. To investigate the role of mitochondrial genetic defects in the development of hypertension, we carried out a systematic and extended mutational screening of 22 tRNA genes in a cohort of 140 
Han Chinese subjects with HTN. Mutational analysis of these tRNA genes in these subjects identified 22 nucleotide changes in 15 different tRNA genes, especially including 3 novel and highly conservative mutations.

\section{Materials and methods}

\subsection{Subjects}

There're 264 subjects, including 140 hypertension patients and 124 controls, ascertained at the Institute of Geriatric Cardiology of Chinese PLA General Hospital, as a part of genetic screening program for hypertension. Hypertension was defined according to the recommendation of the Joint National Committee on Detection, Evaluation and Treatment of High Blood Pressure (JNC VI) [The sixth report of JNC, 1997] as a systolic blood pressure of $140 \mathrm{mmHg}$ or higher and /or a diastolic blood pressure of $90 \mathrm{mmHg}$ or greater., including patients with history of HTN took antihypertension drugs.

All the subjects were interviewed and evaluated to identify both personal or medical histories of hypertension and other clinical abnormalities. The past history, including coronary heart disease (CHD), cerebrovascular disease, diabetes, hyerlipidemia, renal disease, was also evaluated. Coronary heart disease (CHD) is diagnosed on the medical and family histories, the risk factors for CHD, a physical exam, and the results from tests and procedures by the cardiac physicians. Cerebrovascular disease is defined as a neurologic symptom or symptom complex caused by cerebral ischemia or hemorrhage proved by further examination. Diabetes mellitus was defined as hyperglycemia, requiring anti-diabetic drugs or fasting blood sugar over $126 \mathrm{~g} / \mathrm{dL}$. 
Hyperlipidemia was defined as plasma low-density lipoprotein cholesterol (LDL-C) $>130 \mathrm{mg} / \mathrm{dL}$ or total cholesterol (TC) $>200 \mathrm{mg} / \mathrm{dL}$ or using lipid-lowering drugs at the time of investigation. Renal disease usually is made by blood tests measuring BUN, creatinine, and glomerular filtration rate (GFR) less than $90 \mathrm{ml} / \mathrm{min}$. Patients reporting cigarette use within one year prior to examination were considered as smokers. BMI defined as the individual's body mass divided by the square of their height. BMI of 18.5 to $25 \mathrm{~kg} / \mathrm{m}^{2}$ indicates optimal weight, a BMI lower than 18.5 $\mathrm{kg} / \mathrm{m}^{2}$ suggests the person is underweight, a number above $25 \mathrm{~kg} / \mathrm{m}^{2}$ is overweight. DNA samples of the family and 124 healthy controls were acquired for sequence analysis. Informed consents were obtained from all participating members, under protocols approved by the ethics committee of the Chinese PLA General Hospital.

\section{$2.2 \mathrm{mtDNA}$ Sequencing and Sequence Analysis}

Genomic DNA was isolated from whole blood cells of participants using Puregene DNA Isolation Kits (Gentra Systems, Minneapolis, MN, USA). The entire mitochondrial tRNAs of the HTN and controls were PCR amplified in 24 overlapping fragments by use of sets of the light-strand and the heavy strand oligonucleotide primers, as described elsewhere. [M.J., et al., 1998]. Each fragment was purified and subsequently analyzed by direct sequencing in an ABI 3700 automated DNA sequencer (Applied Biosystems, Inc., Foster City, CA, USA) using the Big Dye Terminator Cycle sequencing reaction kit. The entire mitochondrial genomes of four probands $\left(\mathrm{PLAH}_{78-\mathrm{III}-2}, \mathrm{PLAH}_{84-\mathrm{III}-10}\right.$ and $\left.\mathrm{PLAH}_{60-\mathrm{II}-2}, \mathrm{PLAH}_{118-\mathrm{III}-8}\right)$ were also PCR amplified in 24 overlapping fragments as previous desctribed. The resultant sequence 
data were compared with the revised consensus Cambridge sequence (GenBank accession No.NC-012920). [ S. Anderson, et al., 1981]

All 22 tRNA mutations were individually analyzed using the published secondary structures for the tRNAs with the stem and loop structure. [Suzuki, et al., 2011; Ruiz-Pesini, et al., 2006]

\subsection{Phylogenetic analysis}

A total of 17 vertebrates mitochondrial DNA sequences were used in the interspecific analysis. These include: Bos Taurus, Cebus albifrons, Gorilla gorilla, Homo sapiens, Hylobates lar, Lemur catta, Macaca mulatta, Macaca sylvanus, Mus musculus, Nycticebus coucang, Pan paniscus, Pan troglodytes, Papio hamadryas,, Pongo abelii, Pongo pygmaeus, Tarsius bancanus, and Xenopus laevis (Genbank) (Table 2). The conservation index (CI) was calculated by comparing the human nucleotide variants with other 16 vertebrates. The CI was then defined as the percentage of species from the list of 17 different vertebrates that have the wild-type nucleotide at that position.

\subsection{Statistical analysis}

Statistical analyses were performed with the Statistical Package for Social Sciences software (SPSS version 16.0). Continuous variables with normal distributions were expressed as means $\pm \mathrm{SD}$ and compared using a $t$ test. Categorical variables were compared using the chi-square test where appropriate.

\section{Results}

\subsection{Clinical evaluation}


The clinical data showed in table 1 . The average age was $49.2 \pm 15.2$ years in the HTN group (range from 19 to 88 years) versus $56.5 \pm 11.8$ years in the control group (range from 28 to 82 years) with significant difference $(P=0.00)$. The onset age of hypertension was $45.2 \pm 11.9$ years, range from 19 to 76 years old. The BMI of the HTN group was higher than the control group $(26.5 \pm 4.3$ versus $23.7 \pm 3.2, P=0.00)$. The SBP and DBP of the HTN were higher than that of the control, $142.6 \pm 17.3$ versus $118.9 \pm 10.9$ and $92.1 \pm 11.2$ versus $76.8 \pm 7.1$, respectively, both $P<0.01$. The data also showed that there are 39 hypertension patients complicated with CHD, 41 with cerebrovascular disease, 16 with diabetes, 33 with hyperlipidemia and 5 with renal disease. The laboratory test showed no difference of FBS, sodium, potassium, triglyceride, HDL-c, while TC, LDL-cholesterol and creatinine were higher than that of the control group $(P>0.05)$. There're 24 smokers in the hypertension group with no significant difference compared with the control group.

Table 1 clinical data for the hypertensions and the controls

\begin{tabular}{|c|c|c|c|c|c|}
\hline & \multicolumn{2}{|c|}{ Hypertensions $(\mathrm{n}=140)$} & \multirow{2}{*}{$\begin{array}{l}\text { Controls } \\
\text { Mean } \pm \text { SD }\end{array}$} & \multirow{2}{*}{$\begin{array}{l}(\mathrm{n}=124) \\
\text { (Range) }\end{array}$} & \multirow[t]{2}{*}{$P$ value } \\
\hline & Mean \pm SD & (Range) & & & \\
\hline Men, n (\%) & 151 & & 30 & & 0.00 \\
\hline Age (years) & $49.2 \pm 15.2$ & (19 88) & $56.5 \pm 11.8$ & $(28 \sim 82)$ & 0.00 \\
\hline Onset age(years) & $45.2 \pm 11.9$ & $(19 \sim 76)$ & & & \\
\hline BMI $\left(\mathrm{kg} / \mathrm{m}^{2}\right)$ & $26.5 \pm 4.3$ & $(16.02 \sim 38.29)$ & $23.7 \pm 3.2$ & $(18.07 \sim 30.48)$ & 0.00 \\
\hline Systolic BP (mmHg) & $142.6 \pm 17.3$ & $(100 \sim 220)$ & $118.9 \pm 10.9$ & $(105 \sim 138)$ & 0.00 \\
\hline Diastolic BP (mmHg) & $92.1 \pm 11.2$ & $(60 \sim 128)$ & $76.8 \pm 7.1$ & $(54 \sim 78)$ & 0.00 \\
\hline \multicolumn{6}{|l|}{ Past disease } \\
\hline CHD & 39 & & & & \\
\hline Cerebrovacular disease & 41 & & & & \\
\hline Diabetes & 16 & & & & \\
\hline Hyerlipidemia & 33 & & & & \\
\hline Renal disease & 5 & & & & \\
\hline Alcohol & 10 & & 9 & & 0.84 \\
\hline Smoking & 24 & & 17 & & 0.54 \\
\hline
\end{tabular}




\begin{tabular}{llllll}
\hline $\begin{array}{l}\text { Laboratory test } \\
\text { FSB }(\mathrm{mmol} / \mathrm{L})\end{array}$ & $5.74 \pm 1.47$ & $(3.62 \sim 19.08)$ & $\begin{array}{l}5.5 \pm 1.8 \\
(3.94 \sim 18.95)\end{array}$ & & 0.16 \\
& & & & \\
TC $(\mathrm{mmol} / \mathrm{L})$ & $4.78 \pm 0.97$ & $(2.29 \sim 7.55)$ & $4.16 \pm 1.0$ & $(2.36 \sim 6.84)$ & 0.00 \\
Sodium (mmol/L) & $140.57 \pm 3.98$ & $(127.0 \sim 156.7)$ & $140.4 \pm 3.5$ & & 0.68 \\
& & & $(130.3 \sim 148.4)$ & \\
Potassium (mmol/L) & $4.13 \pm 0.39$ & $(3.18 \sim 5.78)$ & $4.37 \pm 0.52$ & $(3.46 \sim 5.72)$ & 0.00 \\
Triglyceride (mmol/L) & $1.56 \pm 0.70$ & $(0.59 \sim 5.87)$ & $1.56+0.89$ & $(0.74 \sim 4.98)$ & 0.99 \\
HDL $(\mathrm{mmol} / \mathrm{L})$ & $1.20 \pm 0.31$ & $(0.49 \sim 2.22)$ & $1.21+0.30$ & $(0.70 \sim 2.20)$ & 0.76 \\
LDL $(\mathrm{mmol} / \mathrm{L})$ & $2.79 \pm 0.88$ & $(0.74 \sim 5.50)$ & $2.11 \pm 0.71$ & $(1.08 \sim 4.21)$ & 0.00 \\
Creatinine $(\mathrm{mol} / \mathrm{L})$ & $69.35 \pm 15.59$ & $(38.0 \sim 133.8)$ & $59.06 \pm 11.76$ & & 0.00 \\
& & & $(32.3 \sim 122.3)$ & & \\
\hline
\end{tabular}

CHD, coronary heart disease; FSB, fasting blood glucose; TC, total cholesterol; HDL, High-density lipoprotein; LDL, low-density lipoprotein; UN, Urea nitrogen.

\subsection{Mutational analysis of mitochondrial 22 tRNA genes}

We sequenced the 22 tRNA genes in probands from 140 hypertension patients and 124 healthy controls. All the variants were compared with the data of mitomap (http://www.mitomap.org) and mtDB (http://www.genpat.uu.se/mtDB). [Wallace, et al., 2003] Comparison with the "Cambridge" reference sequence (CRS) [Anderson, et al., 1981; Andrews, et al., 1999] revealed a total of 22 (9 novel and 13 reported) nucleotide changes in the 15 different tRNA genes (table 2). The novel variants included G586A and T616C in the tRNA ${ }^{\text {Phe }}$, A5823G tRNA ${ }^{\text {Cys }}$, G5856A tRNA ${ }^{\text {Tyr }}$, C7492 tRNA $^{\text {Ser(UCN)}, ~ T 10031 C ~ i n ~ t h e ~ t R N A ~}{ }^{\text {Gly }}, \mathrm{C} 15891 \mathrm{~T}$ and G15930A in the $\mathrm{tRNA}^{\mathrm{Thr}}$, and $\mathrm{T} 16017 \mathrm{C}$ in the tRNA ${ }^{\text {Pro }}$, while the known variants were C4467T in the tRNA $^{\text {Met }}$, T5578C in the tRNA ${ }^{\text {Trp }}$, T5628C in the tRNA ${ }^{\text {Ala }}, A 8296 \mathrm{G}$, G8313A, G8342A in the tRNA ${ }^{\text {Lys }}, \mathrm{T} 10463 \mathrm{C}$ in the $\mathrm{tRNA}^{\mathrm{Arg}}, \mathrm{G} 12147 \mathrm{~A}$ in the tRNA ${ }^{\text {His }}$, C12246A in the tRNA ${ }^{\text {Ser(AGY) }}$, G12300A in the tRNA ${ }^{\text {Leu(CUN) }}, A 15924 G$, G15927A and $\mathrm{A} 15951 \mathrm{G}$ in the $\mathrm{tRNA}^{\mathrm{Thr}}$. All the nucleotide changes were verified by sequence analysis to be homoplasmic. Among 140 subjects with HTN, 26 probands carried at 
least one tRNA variant. 
Table 2. Variants in the mitochondrial tRNA genes in 140 Chinese subjects with EHT and 126 controls.

\begin{tabular}{|c|c|c|c|c|c|c|c|c|c|c|}
\hline tRNA & Position & $\begin{array}{c}\text { Conservation } \\
\text { index }(\%)^{\mathrm{a}}\end{array}$ & Replacement & $\begin{array}{c}\text { Watson-Crick } \\
\text { basepairs }\end{array}$ & Num & $\begin{array}{l}\text { of nucleotides } \\
\text { RNAs }^{\text {b }}\end{array}$ & $\begin{array}{l}\text { No. of } 140 \\
\text { patients(\%) }\end{array}$ & $\begin{array}{l}\text { No. of } 124 \\
\text { controls(\%) }\end{array}$ & $\chi_{\text {value }}^{2} p$ & $\begin{array}{r}\text { Previously } \\
\text { reported }^{\mathrm{d}}\end{array}$ \\
\hline \multirow[t]{2}{*}{$\mathrm{tRNA}^{\mathrm{Phe}}$} & 586 & 100 & $\mathrm{G}$ to $\mathrm{A}$ & $\mathrm{G}-\mathrm{C} \downarrow$ & 10 & D-stem & $1(0.71)$ & $1(0.79)$ & 1 & Yes \\
\hline & 616 & 100 & $\mathrm{~T}$ to $\mathrm{C}$ & A-U $\downarrow$ & 39 & AC stem & $2(1.43)$ & $1(0.79)$ & 0.690 & Yes \\
\hline $\mathrm{tRNA}^{\mathrm{Met}}$ & 4467 & 100 & $\mathrm{C}$ to $\mathrm{T}$ & $\mathrm{G}-\mathrm{C} \downarrow$ & 71 & ACC stem & $2(1.43)$ & $0(0.00)$ & 0.499 & No \\
\hline $\mathrm{tRNA}^{\mathrm{Trp}}$ & 5578 & 100 & $\mathrm{~T}$ to $\mathrm{C}$ & $A-U \downarrow$ & 72 & ACC stem & $2(1.43)$ & $0(0.00)$ & 0.499 & No \\
\hline tRNA $^{\text {Ala }}$ & 5628 & 93.8 & $\mathrm{~T}$ to $\mathrm{C}$ & $A-U \downarrow$ & 31 & $\mathrm{AC}$ stem & $2(1.43)$ & $1(0.79)$ & 0.927 & Yes \\
\hline $\mathrm{tRNA}^{\mathrm{Cys}}$ & 5823 & 50 & A to $G$ & $\mathrm{C}-\mathrm{G} \uparrow$ & 4 & ACC stem & $2(1.43)$ & $0(0.00)$ & 0.499 & No \\
\hline $\mathrm{tRNA}^{\mathrm{Tyr}}$ & 5856 & 100 & $\mathrm{G}$ to $\mathrm{A}$ & $\mathrm{G}-\mathrm{C} \downarrow$ & 40 & AC stem & $1(0.71)$ & $0(0.00)$ & 1 & No \\
\hline $\operatorname{tRNA}^{\operatorname{Ser}(\mathrm{UCN})}$ & 7492 & 81.2 & $\mathrm{C}$ to $\mathrm{T}$ & $\mathrm{A}-\mathrm{U} \uparrow$ & $27 \mathrm{a}$ & D-A junction & $2(1.43)$ & $0(0.00)$ & 0.499 & Yes \\
\hline \multirow[t]{3}{*}{$\mathrm{tRNA}^{\mathrm{Lys}}$} & 8296 & 100 & A to $G$ & A-U $\downarrow$ & 2 & ACC stem & $1(0.71)$ & $1(0.81)$ & 1 & Yes \\
\hline & 8313 & 100 & $\mathrm{G}$ to $\mathrm{A}$ & C-G $\downarrow$ & 24 & D-stem & $2(1.43)$ & $1(0.81)$ & 0.927 & Yes \\
\hline & 8342 & 93.8 & $\mathrm{G}$ to $\mathrm{A}$ & $\mathrm{C}-\mathrm{G} \downarrow$ & 53 & T-stem & $3(2.14)$ & $1(0.81)$ & 0.690 & Yes \\
\hline tRNA $^{\text {Gly }}$ & 10031 & 43.8 & $\mathrm{~T}$ to $\mathrm{C}$ & & 44 & Varible loop & $2(1.43)$ & $0(0.00)$ & 0.499 & No \\
\hline $\mathrm{tRNA}^{\mathrm{Arg}}$ & 10463 & 93.8 & $\mathrm{~T}$ to $\mathrm{C}$ & $\mathrm{U}-\mathrm{A} \uparrow$ & 67 & ACC stem & $1(0.71)$ & $0(0.00)$ & 1 & Yes \\
\hline tRNA $^{\text {His }}$ & 12147 & 100 & $\mathrm{G}$ to $\mathrm{A}$ & $\mathrm{G}-\mathrm{C} \downarrow$ & 10 & D-stem & $2(1.43)$ & $0(0.00)$ & 0.499 & Yes \\
\hline $\operatorname{tRNA}^{\operatorname{Ser}(\mathrm{AGY})}$ & 12246 & 50 & $\mathrm{C}$ to $\mathrm{A}$ & & 54 & T-loop & $1(0.71)$ & $0(0.00)$ & 1 & Yes \\
\hline $\operatorname{tRNA}^{\mathrm{Leu}(\mathrm{CUN})}$ & 12300 & 100 & $\mathrm{G}$ to $\mathrm{A}$ & & 36 & AC loop & $1(0.71)$ & $0(0.00)$ & 1 & Yes \\
\hline \multirow[t]{5}{*}{ tRNA $^{\text {Thr }}$} & 15891 & 87.5 & $\mathrm{C}$ to $\mathrm{T}$ & C-G $\downarrow$ & 4 & ACC stem & $1(0.71)$ & $0(0.00)$ & 1 & No \\
\hline & 15924 & 81.2 & A to $\mathrm{G}$ & U-A $\downarrow$ & 39 & AC stem & $3(2.14)$ & $0(0.00)$ & 0.284 & Yes \\
\hline & 15927 & 56.3 & $\mathrm{G}$ to $\mathrm{A}$ & $\mathrm{C}-\mathrm{G} \downarrow$ & 42 & AC stem & $1(0.71)$ & $5(4.03)$ & 0.170 & Yes \\
\hline & 15930 & 12.5 & $\mathrm{G}$ to $\mathrm{A}$ & & 45 & Varible loop & $2(1.43)$ & $2(1.61)$ & 0.690 & No \\
\hline & 15951 & 62.5 & A to $\mathrm{G}$ & $\mathrm{U}-\mathrm{A} \downarrow$ & 71 & ACC stem & $1(0.71)$ & $2(1.61)$ & 0.927 & Yes \\
\hline tRNA $^{\text {Pro }}$ & 16017 & 56.3 & $\mathrm{~T}$ to $\mathrm{C}$ & $A-U \downarrow$ & 7 & ACC stem & $1(0.71)$ & $0(0.00)$ & 1 & No \\
\hline $\mathrm{CI}>75 \%$ & & & & & & & $26(18.6)$ & $6(4.8)$ & 0.00 & \\
\hline
\end{tabular}


${ }^{a}$ The conservation index (CI) was then defined as the percentage of the human nucleotide variants with other 16 vertebrates that have the wild-type nucleotide at that position.

${ }^{\mathrm{b}}$ Numberts represent the nucleotide positions according to the tRNAdb numbering system (Sprinzl et al., Nucleic Acids Res., 1998, 26(1):148-53) and mitotRNAdb http://mttrna.bioinf.uni-leipzig.de/mtDataOutput. Symbol “-” represents nucleotides that are not conserved in the numbering system for canonical tRNAs. ACC, Acceptor; AC, Anticodon; A-D Junction, nucleotides between acceptor stem and D-stem; D-A Junction, nucleotides between D-stem and anticodon stem.

${ }^{\mathrm{c}}$ See http://www.genpat.uu.se/mtDB

${ }^{\mathrm{d}}$ According to MITOMAP (http://www.mitomap.org/MITOMAP). Database of mtDNA Coding Region \& RNA Sequence Variants was last edited on Dec 11, 2013, while that of

Reported Mitochondrial DNA Base Substitution Diseases: rRNA/tRNA mutations was last edited on Dec 18, 2013. 


\subsection{Evaluation of mitochondrial $t R N A$ variants}

To identify putative deleterious mutation, these variants were further evaluated using following three criteria: 1). Present $<1 \%$ in the controls; 2 ). CI is $>75 \%$, proposed by Ruiz-Pesini and Wallace [Ruiz-Pesini, et al., 2006]; 3). Potential structural and functional alterations. First, we used the secondary structure of tRNAs to localize each variant with either a stem or a loop and to analyze if the base changes within stems alter classic Watson-Crick (WC) base pair. There are 17 variants located at the stems of tRNAs, while 5 variants occurred in the loops of tRNAs (figure 1). Here, we identified the A5823G variant in the $\mathrm{RRNA}^{\mathrm{Cys}}$ contributed to a putative C-G base-pairing and $\mathrm{T} 10463 \mathrm{C}$ in the $\mathrm{RRNA}^{\mathrm{Arg}}$ created to a putative U-A base-pairting, while the other variants in the stem of tRNAs abolished a putative base pairing(s) (Table 2 and Figure 1). In addition, we also performed a phylogenetic analysis by comparing the human tRNA nucleotide variants with those in other 16 vertebrates. As shown in Table 2, CI among the variants ranged from $12.5 \%$ (tRNA $^{\text {Thr }}$ G15930A variant) to $100 \%\left(\mathrm{G} 586 \mathrm{~A}\right.$ and $\mathrm{T} 616 \mathrm{C}$ in the $\mathrm{tRNA}^{\mathrm{Phe}}$, tRNA ${ }^{\mathrm{Met}} \mathrm{C} 4467 \mathrm{~T}$, tRNA ${ }^{\text {Trp }}$ T5578C, tRNA ${ }^{\text {Tyr }}$ G5856A, A8296G and G8313A in the tRNA ${ }^{\text {Lys }}$, tRNA ${ }^{\text {His }}$ G12147A and tRNA ${ }^{\text {Leu(CUN) }} \mathrm{G} 12300 \mathrm{~A}$ variants). There are 15 variants with $\mathrm{CI}>75 \%, 5$ variants with CI between $75 \%$ and $50 \%$ and 2 variants with CI $<50 \%$. These variants were then evaluated by examining the allelic frequency in 124 Han Chinese control population. In the 15 variants with $\mathrm{CI}>75 \%$, there were 9 variants absent in these Chinese control population, including tRNAMet C4467T, tRNATrp T5578C, 
tRNATyr G5856A, tRNA ${ }^{\text {Ser(UCN) }}$ C7492T, tRNA ${ }^{\text {Arg }}$ T10463C, tRNA ${ }^{\text {His }}$ G12147A, tRNA $^{\text {Leu(CUN) }}$ G12300A,C15891T and A15924G.. Based on these criteria, these 15 variants may have functional significance, including the G586A and T616C in tRNA $^{\text {Phe }}$, tRNA ${ }^{\text {Met }}$ C4467T, tRNA ${ }^{\text {Trp }}$ T5578C, tRNA ${ }^{\text {Ala }}$ T5628C, tRNA ${ }^{\text {Tyr }}$ G5856A, tRNA $^{\text {Ser(UCN) }}$ C7492T, A8296G, G8313A and G8342A in the tRNA ${ }^{\text {Lys }}$, tRNA ${ }^{\text {Arg }}$ T10463C, tRNA $^{\text {His }}$ G12147A, tRNA ${ }^{\text {Leu(CUN) }}$ G12300A, C15891T and A15924G in the tRNA $^{\text {Thr }}$. The higher $p$-value showed no difference between the hypertension and the control group, due to small size of subjects. But there are 26 patients with CI larger than $75 \%$ in the HTN group, higher than the 6 subjects in the control group $(P=0.00)$. 

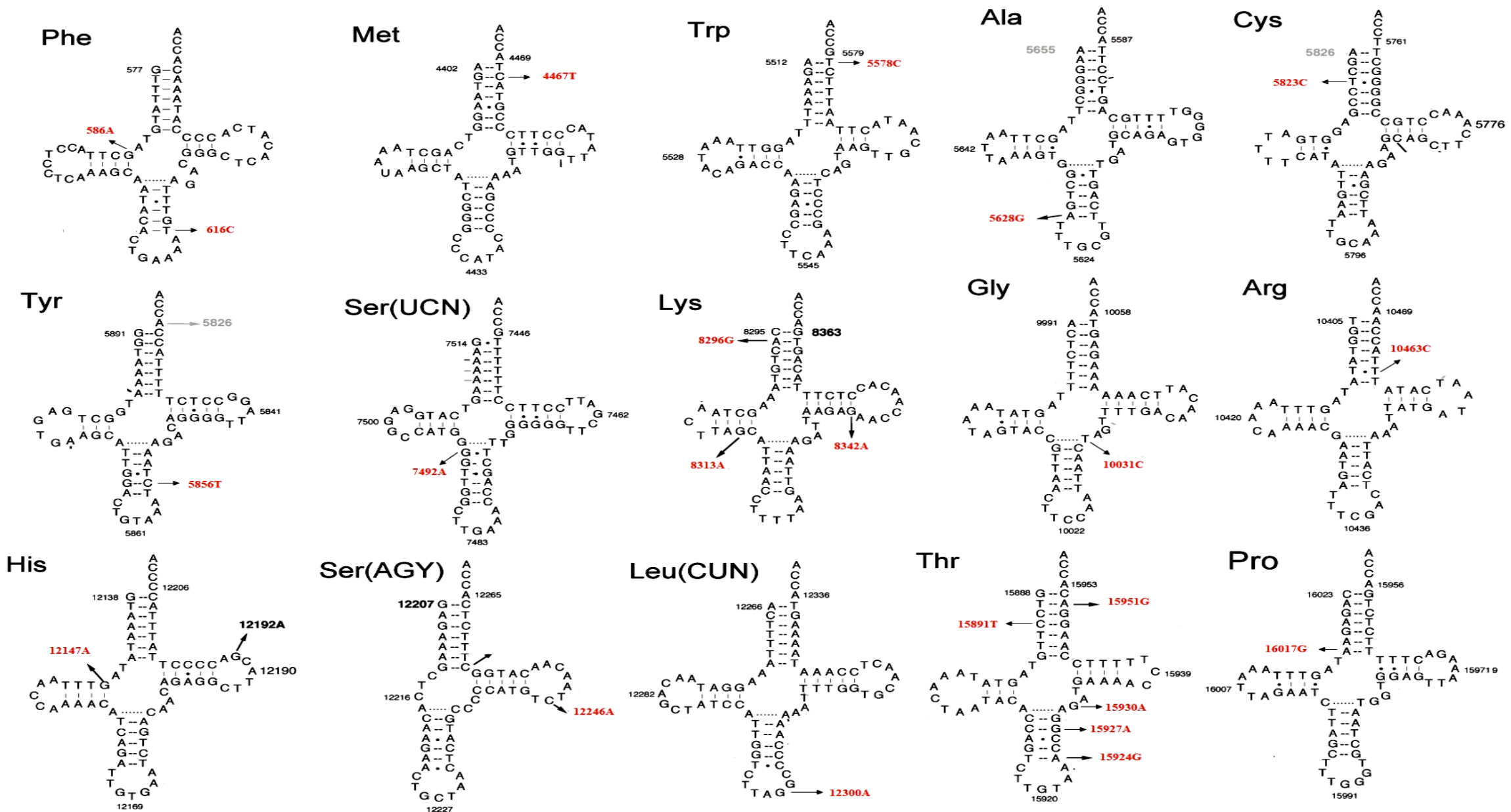

Figure 1. Mitochondrial tRNA variants in Chinese subjects with hypertension. Cloverleaf structures of canonical tRNA and nine mitochondrial tRNAs are shown. Circled numbers represent the nucleotide positions according to the conventional tRNA numbering system. Tertiary interactions between nucleotides are indicated by dotted lines. Arrows indicate the position of the tRNA mutations. 
3.4.Clinical and genetic evaluation of 4 Chinese Han families presented with maternally inherited hypertension

According to the results of the structure and function analysis of tRNAs, we identified 13 variants might be associated with hypertension, involved 19 families. In these families, there are 4 families presented with maternally inherited hypertension with other families no family history of hypertension or inconsistent with maternal pattern, which was substantiated with the method by Sun et al [Sun, et al., 2003]. The four probands included $\mathrm{PLAH}_{84}$ with tRNA ${ }^{\mathrm{Met}} \mathrm{C} 4467 \mathrm{~T}, \mathrm{PLAH}_{78}$ with tRNA ${ }^{\text {Trp }}$ T5578C, $\mathrm{PLAH}_{60}$ with tRNA ${ }^{\text {Ala }}$ T5628C, $\mathrm{PLAH}_{118}$ with tRNA ${ }^{\mathrm{Ser}(\mathrm{UCN})}$ C7492T. The four probands and their family members underwent further physical examination, and laboratory tests. The proband $\mathrm{PLAH}_{78}$ was female and her mother (II-2), her sister (III-6) and the son of her sister (IV-6) also presented with hypertension. None of her brother (III-3) or his children (IV-3 and IV-5) affected. The proband $\mathrm{PLAH}_{84}$ was male and none of his children (IV-7 and IV-8) presented with hypertension. His mother (II-2), all of his sisters (III-2, III-4, III-6, III-8 and III-9) and one daughter of his sister (IV-3) presented with hypertension. None of his children (IV-7 and IV-8) or his uncle's children (III-12 and III-14) presented with hypertension. The $\mathrm{PLAH}_{60}$ was a female and her mother (I-2) and one daughter (III-1) presented with hypertension. Although one of her brothers (II-3) presented with hypertension, none of his children (III-3 and III-4) affected. The proband $\mathrm{PLAH}_{118}$ was a female and her mother (II-2), two brother (III-1 and III-2), and three out of her sisters (III-6, III-10 and III-12) presented with hypertension. Her daughter (IV-12) and one son of her sisters (IV-13) also presented with hypertension. None of her brothers' children or her uncle's children affected. All of these four families presented with maternally inherited 
pattern. 

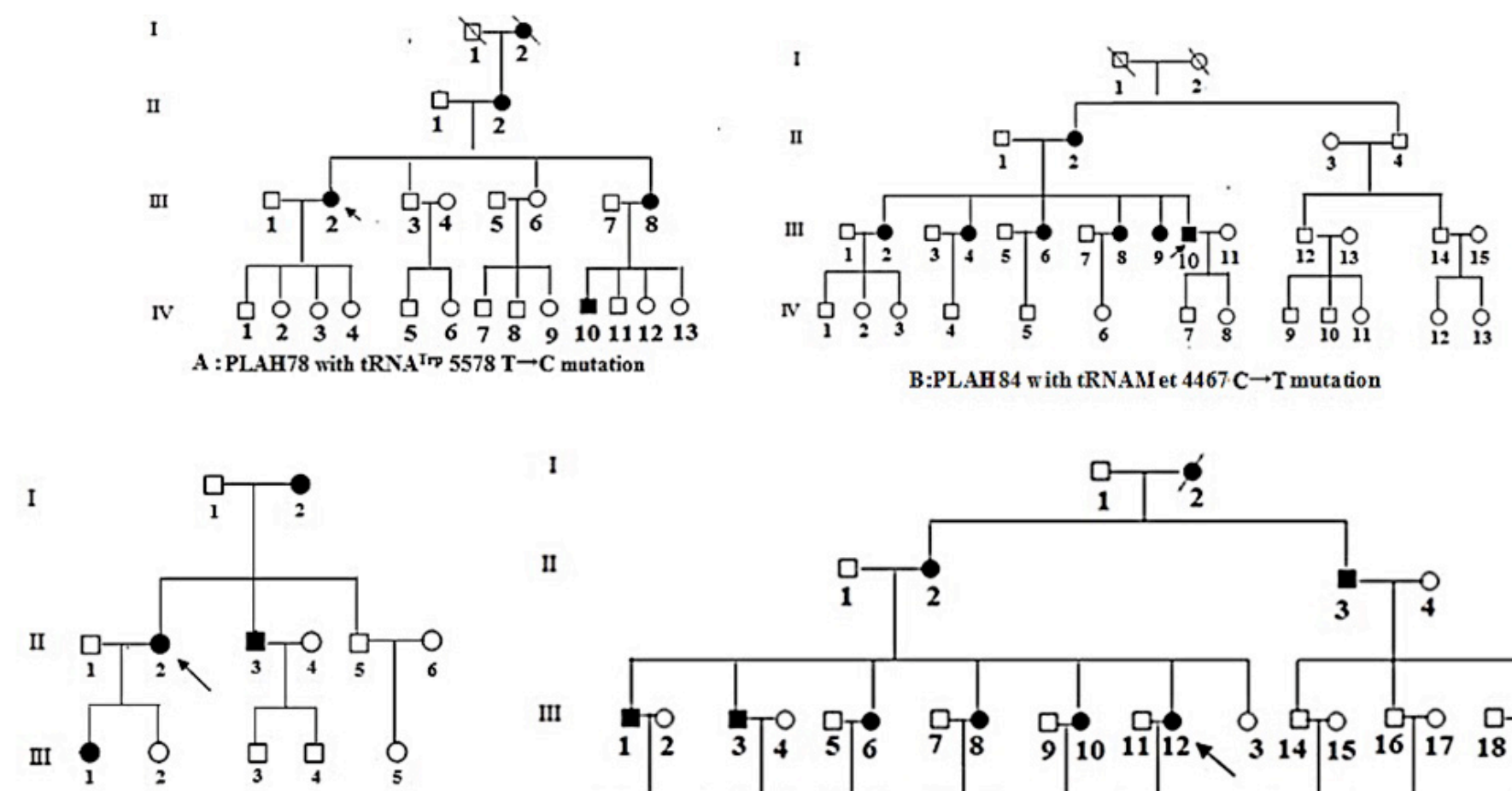

II

III

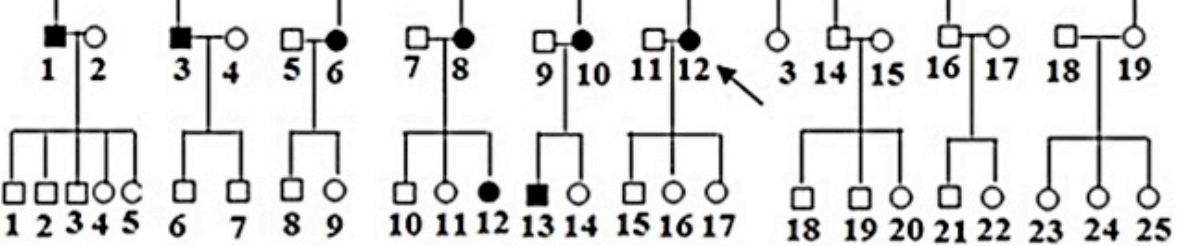

D:PLAHI18 with tRNASer(UCN) $7492 \mathrm{C} \rightarrow \mathrm{T}$ mutation

Figure 2. Four Han Chinese pedigrees with hypertension. Affected individuals are indicated by filled symbols. An arrow denotes probands. 


\subsection{Mutational analysis of mitochondrial genomes}

To evaluate the contribution of mtDNA variants or haplogroups to the phenotypic expression of these putative mtDNA mutations in these Chinese pedigrees, a PCR-amplification of fragments spanning entire mtDNA and subsequent DNA sequence analysis was performed in 4 probands, including $\mathrm{PLAH}_{84}$ with tRNA ${ }^{\mathrm{Met}}$ C4467T, PLAH $_{78}$ with tRNA ${ }^{\text {Trp }}$ T5578C, PLAH $_{60}$ with tRNA ${ }^{\text {Ala }}$ T5628C, PLAH $_{118}$ with tRNA ${ }^{\mathrm{Ser}(\mathrm{UCN})} \mathrm{C} 7492 \mathrm{~T}$. The sequence results from these Chinese subjects were aligned with the updated consensus Cambridge sequence (see table 3). The probands from the four families exhibited distinct sets of mtDNA polymorphisms. These included 23 variants in the D-loop region, 4 known variants in the $12 \mathrm{~S}$ rRNA gene, 5 known variants in the $16 \mathrm{~S}$ rRNA gene, the known tRNA ${ }^{\text {Ala }}$ T5628C and tRNA ${ }^{\text {Ser(UCN) }}$ C7492T, the unknown tRNA ${ }^{\text {Met }}$ C4467T and tRNA ${ }^{\text {Trp }}$ T5578C, and other 29 known mutations in the polypeptide encoding genes. [Ruiz-Pesini, et al., 2006] All the variants in the RNAs were further evaluated by phylogenetic analysis of these variants and sequences from other 16 organisms including mouse, [Bibb, 1981] bovine, [Gadaleta, 1989] and Xenopus laevis. [Roe, et al., 1985] Only the known 12S rRNA T1005C variant of subject PLAH118 had been reported associated with hearing loss with high conservation. These data suggest that the 12S rRNA T1005C variant may have a interaction with the tRNA ${ }^{\text {Ser(UCN) }}$ C7492T mutation in the phenotypic manifestation of hypertension. By contrast, none of other variants showed both evolutionary conservation and $<1 \%$ frequency of 2704 mtDNAs (See http://www.genpat.uu.se/mtDB) 
Table 3. mtDNA variants in three Han Chinese probands with coronary heart disease

\begin{tabular}{|c|c|c|c|c|c|c|c|c|c|}
\hline Gene & Position & Replacement & $\begin{array}{l}\text { Conservation } \\
(\mathrm{H} / \mathrm{B} / \mathrm{M} / \mathrm{X})^{\mathrm{a}}\end{array}$ & CRS & PLAH-78 & PLAH-84 & PLAH-60 & PLAH-118 & $\begin{array}{l}\text { Previous } \\
\text { reported }\end{array}$ \\
\hline \multirow[t]{14}{*}{ D-loop } & 64 & $\mathrm{C}$ to $\mathrm{T}$ & & $\mathrm{C}$ & $\mathrm{T}$ & & $\mathrm{T}$ & & Yes \\
\hline & 73 & A to $G$ & & A & & $\mathrm{G}$ & G & $\mathrm{G}$ & Yes \\
\hline & 146 & $\mathrm{~T}$ to $\mathrm{C}$ & & $\mathrm{T}$ & & & $\mathrm{C}$ & & Yes \\
\hline & 152 & $\mathrm{~T}$ to $\mathrm{C}$ & & $\mathrm{T}$ & & $\mathrm{C}$ & & & Yes \\
\hline & 186 & $\mathrm{C}$ to $\mathrm{G}$ & & $\mathrm{C}$ & $\mathrm{G}$ & & $\mathrm{G}$ & & Yes \\
\hline & 204 & $\mathrm{~T}$ to $\mathrm{G}$ & & $\mathrm{T}$ & G & & & & Yes \\
\hline & 235 & A to $\mathrm{G}$ & & A & & & & $\mathrm{G}$ & Yes \\
\hline & 248 & A to Del & & $\mathrm{A}$ & Del & & Del & Del & Yes \\
\hline & 263 & A to $G$ & & $\mathrm{~A}$ & $\mathrm{G}$ & $\mathrm{G}$ & $\mathrm{G}$ & $\mathrm{G}$ & Yes \\
\hline & 310 & $\mathrm{~T}$ to $\mathrm{C}$ & & $\mathrm{T}$ & & $\mathrm{C}$ & $\mathrm{C}$ & $\mathrm{C}$ & Yes \\
\hline & 489 & $\mathrm{~T}$ to $\mathrm{C}$ & & $\mathrm{T}$ & & $\mathrm{C}$ & & & Yes \\
\hline & 494 & $\mathrm{C}$ to Del & & $\mathrm{C}$ & Del & & & & Yes \\
\hline & 515 & A to Del & & A & Del & & & & Yes \\
\hline & 522 & $\mathrm{C}$ to Del & & $\mathrm{C}$ & Del & & & & Yes \\
\hline \multirow[t]{4}{*}{ 12SrRNA } & 750 & A to $\mathrm{G}$ & $\mathrm{A} / \mathrm{A} / \mathrm{G} /-$ & A & $\mathrm{G}$ & & & $\mathrm{G}$ & Yes \\
\hline & 1005 & $\mathrm{~T}$ to $\mathrm{C}$ & $\mathrm{T} / \mathrm{T} / \mathrm{T} / \mathrm{T}$ & $\mathrm{T}$ & & & & $\mathrm{C}$ & Yes \\
\hline & 1382 & A to $\mathrm{C}$ & $\mathrm{A} / \mathrm{A} / \mathrm{A} / \mathrm{G}$ & A & & $\mathrm{C}$ & & & Yes \\
\hline & 1438 & A to $G$ & $\mathrm{~A} / \mathrm{A} / \mathrm{A} / \mathrm{G}$ & $\mathrm{A}$ & $\mathrm{G}$ & $\mathrm{G}$ & $\mathrm{G}$ & $\mathrm{G}$ & Yes \\
\hline \multirow[t]{5}{*}{ 16SrRNA } & 1734 & $\mathrm{C}$ to $\mathrm{T}$ & $\mathrm{C} / \mathrm{A} / \mathrm{T} / \mathrm{A}$ & $\mathrm{C}$ & & & $\mathrm{T}$ & & Yes \\
\hline & 2706 & A to $G$ & $\mathrm{~A} / \mathrm{G} / \mathrm{A} / \mathrm{A}$ & A & $\mathrm{G}$ & $\mathrm{G}$ & G & $\mathrm{G}$ & Yes \\
\hline & 2755 & A to $G$ & & $\mathrm{~A}$ & & & $\mathrm{G}$ & & Yes \\
\hline & 3010 & $\mathrm{G}$ to $\mathrm{A}$ & $\mathrm{G} / \mathrm{G} / \mathrm{A} / \mathrm{A}$ & G & & A & & & Yes \\
\hline & 3107 & $\mathrm{C}$ to Del & $\mathrm{C} / \mathrm{T} / \mathrm{T} / \mathrm{T}$ & $\mathrm{C}$ & Del & Del & Del & Del & Yes \\
\hline \multirow[t]{3}{*}{ ND1 } & 3970 & $\mathrm{C}$ to $\mathrm{T}$ & & $\mathrm{C}$ & $\mathrm{T}$ & $\mathrm{T}$ & & $\mathrm{T}$ & Yes \\
\hline & 4086 & $\mathrm{C}$ to $\mathrm{T}$ & & $\mathrm{C}$ & $\mathrm{T}$ & & & & Yes \\
\hline & 4260 & $\mathrm{C}$ to $\mathrm{A}$ & & $\mathrm{C}$ & & A & & & Yes \\
\hline $\mathrm{tRNA}^{\mathrm{Met}}$ & 4467 & $\mathrm{C}$ to $\mathrm{T}$ & & & & $\mathrm{T}$ & & & No \\
\hline ND2 & 4769 & A to $G$ & & A & & & & $\mathrm{G}$ & Yes \\
\hline $\mathrm{tRNA}^{\mathrm{Trp}}$ & 5578 & $\mathrm{~T}$ to $\mathrm{C}$ & & $\mathrm{T}$ & $\mathrm{C}$ & & & & No \\
\hline
\end{tabular}




\begin{tabular}{|c|c|c|c|c|c|c|c|c|c|}
\hline tRNA $^{\text {Ala }}$ & 5628 & $\mathrm{~T}$ to $\mathrm{C}$ & $\mathrm{T} / / \mathrm{T} / \mathrm{T} / \mathrm{T}$ & $\mathrm{T}$ & & & $\mathrm{C}$ & & Yes \\
\hline \multirow[t]{2}{*}{ COI } & 6962 & $\mathrm{G}$ to $\mathrm{A}$ & & G & A & & A & & Yes \\
\hline & 7028 & $\mathrm{C}$ to $\mathrm{T}$ & & $\mathrm{C}$ & $\mathrm{T}$ & & $\mathrm{T}$ & $\mathrm{T}$ & Yes \\
\hline $\mathrm{tRNA}^{\mathrm{Ser}}$ & 7492 & $\mathrm{C}$ to $\mathrm{T}$ & & $\mathrm{C}$ & & & & $\mathrm{T}$ & Yes \\
\hline ATPase 8 & 8414 & $\mathrm{C}$ to $\mathrm{T}$ & $\mathrm{L} / \mathrm{F} / \mathrm{M} / \mathrm{L}$ & $\mathrm{C}$ & & $\mathrm{T}$ & & & Yes \\
\hline \multirow[t]{2}{*}{ ATPase 6} & 8701 & A to $G$ & $\mathrm{~T} / \mathrm{S} / \mathrm{L} / \mathrm{Q}$ & A & & G & & & Yes \\
\hline & 8860 & A to $G$ & $\mathrm{~T} / \mathrm{A} / \mathrm{A} / \mathrm{T}$ & A & & & G & G & Yes \\
\hline Cyt C III & 9824 & $\mathrm{~T}$ to $\mathrm{A}$ & & $\mathrm{T}$ & & $\mathrm{A}$ & & & Yes \\
\hline \multirow[t]{3}{*}{ NADHase 3} & 10310 & $\mathrm{G}$ to $\mathrm{A}$ & & G & A & & A & A & Yes \\
\hline & 10398 & A to $G$ & $\mathrm{~T} / \mathrm{T} / \mathrm{T} / \mathrm{A}$ & A & & G & & & Yes \\
\hline & 10400 & $\mathrm{C}$ to $\mathrm{T}$ & & $\mathrm{C}$ & & $\mathrm{T}$ & & & Yes \\
\hline \multirow[t]{2}{*}{ ND4L } & 10586 & $\mathrm{G}$ to $\mathrm{A}$ & & G & & & & A & Yes \\
\hline & 10609 & $\mathrm{~T}$ to $\mathrm{C}$ & $\mathrm{M} / \mathrm{T} / \mathrm{T} / \mathrm{T}$ & $\mathrm{T}$ & $\mathrm{C}$ & & $\mathrm{C}$ & & Yes \\
\hline \multirow[t]{2}{*}{ NADH4 } & 10873 & $\mathrm{~T}$ to $\mathrm{C}$ & & $\mathrm{T}$ & & $\mathrm{C}$ & & & Yes \\
\hline & 11719 & $\mathrm{G}$ to $\mathrm{A}$ & & G & $\mathrm{A}$ & A & A & A & Yes \\
\hline \multirow[t]{4}{*}{ ND5 } & 12338 & $\mathrm{~T}$ to $\mathrm{C}$ & & $\mathrm{T}$ & & & & $\mathrm{C}$ & Yes \\
\hline & 12406 & $\mathrm{G}$ to $\mathrm{A}$ & $\mathrm{V} / \mathrm{F} / \mathrm{S} / \mathrm{F}$ & $\mathrm{G}$ & $\mathrm{A}$ & & A & & Yes \\
\hline & 13708 & $\mathrm{G}$ to $\mathrm{A}$ & & G & & & & A & Yes \\
\hline & 13928 & $\mathrm{G}$ to $\mathrm{C}$ & $\mathrm{S} / \mathrm{T} / \mathrm{S} / \mathrm{T}$ & $\mathrm{G}$ & $\mathrm{C}$ & & $\mathrm{C}$ & $\mathrm{C}$ & Yes \\
\hline \multirow[t]{2}{*}{ ND6 } & 14587 & A to $G$ & & A & & G & & & Yes \\
\hline & 14668 & $\mathrm{C}$ to $\mathrm{T}$ & & $\mathrm{C}$ & & $\mathrm{T}$ & & & Yes \\
\hline \multirow[t]{6}{*}{ Cyt b } & 14783 & $\mathrm{~T}$ to $\mathrm{C}$ & & $\mathrm{T}$ & & $\mathrm{C}$ & & & Yes \\
\hline & 15043 & $\mathrm{G}$ to $\mathrm{A}$ & & G & & A & & & Yes \\
\hline & 15301 & $\mathrm{G}$ to $\mathrm{A}$ & & G & & A & & & Yes \\
\hline & 15326 & A to $G$ & $\mathrm{~T} / \mathrm{M} / \mathrm{I} / \mathrm{I}$ & A & G & G & & $\mathrm{G}$ & Yes \\
\hline & 15823 & $\mathrm{C}$ to $\mathrm{T}$ & & $\mathrm{C}$ & $\mathrm{T}$ & & & & Yes \\
\hline & 15824 & A to $G$ & & A & G & & & & Yes \\
\hline \multirow[t]{5}{*}{ D-loop } & 16129 & $\mathrm{G}$ to $\mathrm{A}$ & & $\mathrm{G}$ & A & & & & Yes \\
\hline & 16172 & $\mathrm{~T}$ to $\mathrm{C}$ & & $\mathrm{T}$ & $\mathrm{C}$ & & & & Yes \\
\hline & 16189 & $\mathrm{~T}$ to $\mathrm{C}$ & & $\mathrm{T}$ & & & $\mathrm{C}$ & & Yes \\
\hline & 16223 & $\mathrm{C}$ to $\mathrm{T}$ & & $\mathrm{C}$ & & $\mathrm{T}$ & & & Yes \\
\hline & 16258 & A to $\mathrm{C}$ & & A & & & $\mathrm{C}$ & & Yes \\
\hline
\end{tabular}




\begin{tabular}{ccccccc}
\hline 16293 & A to C & A & & & \\
16311 & T to C & T & Y & C \\
16362 & T to C & T & Y & Yes \\
16519 & T to C & T & C & C \\
\hline
\end{tabular}

*Conservation of amino acid for polypepides or nucleotide for RNAs in human (H), bovine (B), mouse (M), and Xenopus laevis (X);

${ }^{\dagger} \mathrm{CRS}$ : Cambridge reference sequence;

† See the online mitochondrial genome database http://www.mitomap.org and http://www.genpat.uu.se/mtDB/ 


\section{Discussion}

In this study, we did complete sequencing analysis of the whole 22 mitochondrial tRNAs and the clinical, genetic and molecular characterization of 140 hypertension and 124 healthy controls. The clinical data showed that the HDL-cholesterol of the hypertension subjects were lower than that of control. Similarly, wilson et al reported in a large kindred with a metabolic disorder including hypertension, hypercholesterolemia, and hypomagnesemia [Frederick, et al., 2004]. Mutational analysis of mitochondrial tRNA genes identified 22 variants. These variants were further evaluated for the evolutional conservation, lower frequency in the controls and $2704 \mathrm{mtDNAs}$, the potential structural and functional alterations and maternal transmission of hypertension in matrilineal relatives carrying one of tRNA mutations. Of these variants, tRNA ${ }^{\text {Met }}$ C4467T, tRNA ${ }^{\text {Trp }}$ T5578C, tRNA ${ }^{\text {Ala }}$ T5628C and tRNA $^{\text {Ser(UCN) }}$ C7492T were highly conserved and with potential structural and functional alterations, suggesting that these mutations may be associated with hypertension.

All the probands' families carried with 22 tRNAs were evaluated. Four of them were consistent with maternal pattern. Maternal influences on BP can be explained by X-chromosomal inheritance, chromosomal imprinting [Reik, et al., 2001], gestational [Miller, et al., 1987; Alexander, et al., 2006] mechanisms and mitochondrial disorders [Giles, et al., 1980]. For autosomal inheritance, the morbidity of offspring of affected mothers should be equal to that of the affected fathers. However, none of the offsprings of affected fathers from these families had hypertension, so the autosomal inheritance could be rejected. For X-linked inheritance, only the female could be affected, but all these families had both male and female patients, so X-linked 
inheritance could be rejected. As for gestational mechanisms, could be excluded since the ratio of affected offspring of hypertension mother should be less than 50 percent, while those of these families were larger or equal to 50 percent. By far the mitochondrial DNA abnormal is the most likely explanation of etiology of hypertension for these pedigrees.

Human (mammalian) mtDNA encodes 13 essential subunits of the inner membrane complex responsible for OXPHOS. These mRNAs are translated by the mitochondrial protein synthesis machinery, which uses the 22 species of mitochondrial tRNAs (mt tRNAs) encoded by mtDNA. The unique structural features of mt tRNAs distinguish them from cytoplasmic tRNAs bearing the canonical cloverleaf structure. The genes encoding mt tRNAs are highly susceptible to point mutations, which are a primary cause of mitochondrial dysfunction and are associated with a wide range of pathologies. Approximately 200 pathogenic mutations have been mapped to mt tRNA genes (http://www.mitomap.org/MITOMAP), emphasizing the importance of $\mathrm{mt}$ tRNAs for mitochondrial function. The structure of tRNA can be decomposed into its primary structure, usually visualized as the cloverleaf structure. The acceptor stem with 7-base pair (bp) stem is made by the base pairing of the 5'-terminal nucleotide with the 3'-terminal nucleotide (which contains the CCA 3'-terminal group used to attach the amino acid). The acceptor stem may contain non-Watson-Crick base pairs. The anticodon arm is a 5 to $6 \mathrm{bp}$ stem whose loop contains the anticodon. The D arm is a $4 \mathrm{bp}$ stem ending in a loop that often contains dihydrouridine. The $\mathrm{T}$ arm is a 3-5 bp stem containing the sequence $\mathrm{T} \Psi \mathrm{C}$ where $\Psi$ is a pseudouridine.

In this study, the C4467T mutation is first reported, which is localized at a highly conserved cytosine $(71 \mathrm{C})$ on the acceptor stem of the tRNA ${ }^{\mathrm{Ala}}$. The position is important for the stability and identity of tRNA. The C-to-T transition at this position 
by the $\mathrm{C} 4467 \mathrm{~T}$ mutation is expected to alter the secondary structure and stability of tRNA $^{\text {Ala }}$. Similarly, previous study reported that A3302G at the highly conserved (2U-71A) aminoacyl stem of tRNA ${ }^{\text {Leu(UUR) }}$ was associated with abnormal mitochondrial RNA processing and contributed to mitochondrial myopathy. [Maniura-Weber, et al., 2006] We also identified the novel T5578C mutation was localized at a highly conserved thymine $(72 \mathrm{~T})$ on the acceptor stem of the tRNA ${ }^{\mathrm{Trp}}$, which is important to the secondary structure and stability of tRNA ${ }^{\text {Trp }}$. Silvestri et al [Silvestri, et al., 1994] reported an infant with a maternally inherited cardiomyopathy was associated with tRNA ${ }^{\text {Leu(UUR) }}$ C3303T (destablized a highly conservative base-pairing (1G-72C) on the acceptor stem of this tRNA). The other novel reported mutation, tRNA ${ }^{\text {Ser(UCN) }} \mathrm{C} 7492 \mathrm{~T}$, was localized at a highly conserved $27 \mathrm{a}$ D-A junction, where the position is expected to create a highly conservative base-pairing $(27 \mathrm{U}-43 \mathrm{~A})$ on the acceptor stem of this tRNA, alter the secondary structure of this tRNA. Finally, tRNA ${ }^{\text {Ala }}$ T5628C had been reported before that was associated with chronic progressive external ophthalmoplegia, dysphagia and mild proximal myopathy, which was located on the highly conserved A-U base pair within the anticodon stem of the tRNA ${ }^{\mathrm{Ala}}$. [Spagnolo, et al., 2001] These three novel muatations, as tRNA $^{\text {Met }}$ C4467T, tRNA ${ }^{\text {Trp }}$ T5578C and tRNA ${ }^{\text {Ser(UCN) }}$ C7492T fulfills the suggested criteria for the definition of disease-related nucleotide base change: i) disrupt an evolutionary highly conserved base pair located in the anticodon stem ii) demonstrate a situation of heteroplasmy in patient's blood iii) the mutation was absent in controls and in patients with mitochondrial disorders associated with known mtDNA mutations.

\section{Conclusion}

The major findings of this study are that tRNAs mutations, associated with altered 
structures of tRNAs and mitochondrial dysfunction, may contribute to the hypertension in Chinese population. These variants, tRNA ${ }^{\text {Met }}$ C4467T, tRNA ${ }^{\text {Trp }}$ T5578C, tRNA ${ }^{\text {Ala }}$ T5628C and tRNA ${ }^{\text {Ser(UCN) }}$ C7492T were highly conserved and altered structure and function of their tRNAs, thereby causing mitochondrial dysfunctions. These four mutations may be the inherited risk factors for hypertension. Thus, our findings may provide new insights into the understanding of pathophysiology and valuable information for management and treatment of hypertension.

\section{Acknowledgments}

This work was supported by National Institutes of Health (NIH) grant RO1DC07696 from the National Institute on Deafness and Other Communication Disorders, a research grant (206-08) from the Ministry of Science and Technology, Wenzhou City Government, China to MXG and National Science Foundation of China to Y.Q. Liu (NO: 81100186/H0214 and 81470542/H0214).

Reference:

Alexander BT, 2006. Fetal programming of hypertension. Am J Physiol Regul Integr Comp Physiol 290:R1-R10.

Anderson S, Bankier AT, Barrell BG, de Bruijn MH, Coulson AR, Drouin J, Eperon IC, Nierlich DP, Roe BA, Sanger F, Schreier PH, Smith AJ, Staden R, Young IG, 1981. Sequence and organization of the human mitochondrial genome. Nature 290:457-465.

Andrews RM, Kubacka I, Chinnery PF, Lightowlers RN, Turnbull DM, Howell N, 1999. Reanalysis and revision of the Cambridge reference sequence for human 
mitochondrial DNA. Nat Genet, 23:147.

Bengtsson B, Thulin T, Scherstén B, 1979. Familial resemblance in casual blood pressure--a maternal effect? Clin Sci (Lond). 57 Suppl 5:279s-281s.

Bibb MJ, Van Etten RA, Wright CT, Walberg MW, and Clayton DA, 1981. Sequence and gene organization of mouse mitochondrial DNA. Cell 26:167-180.

Chobanian AV, Bakris GL, Black HR, Cushman WC, Green LA, Izzo JL Jr, Jones DW, Materson BJ, Oparil S, Wright JT Jr, Roccella EJ; Joint National Committee on Prevention, Detection, Evaluation, and Treatment of High Blood Pressure. National Heart, Lung, and Blood Institute; National High Blood Pressure Education Program Coordinating Committee, 2003. Joint National Committee on Prevention, Detection, Evaluation, and Treatment of High Blood Pressure. National Heart, Lung, and Blood Institute; National High Blood Pressure Education Program Coordinating Committee. Seventh report of the Joint National Committee on Prevention, Detection, Evaluation, and Treatment of High Blood Pressure. Hypertension 42(6):1206-52.

DeStefano AL, Gavras H, Heard-Costa N, Bursztyn M, Manolis A, Farrer LA, Baldwin CT, Gavras I, Schwartz F, 2001. Maternal component in the familial aggregation of hypertension. Clin Genet 60:13-21.

Frederick H. Wilson, Ali Hariri1, Anita Farhi1, Hongyu Zhao, Kitt Falk Petersen, Hakan R. Toka1, Carol Nelson-Williams, Khalid M. Raja, Michael Kashgarian, Gerald I. Shulman, Steven J. Scheinman8, and Richard P. Lifton, 2004. A Cluster of Metabolic Defects Caused by Mutation in a Mitochondrial tRNA. Science 12; 306(5699): 1190-1194.

Gadaleta G, Pepe G, De Candia G, Quagliariello C, Sbisa E, and Saccone C, 1989. The complete nucleotide sequence of the Rattus norvegicus mitochondrial genome: Cryptic signals revealed by comparative analysis between vertebrates. $\mathrm{J}$ Mol Evol 28:497-516.

Giles RE, Blanc H, Cann HM, Wallace DC, 1980. Maternal inheritance of human mitochondrial DNA. Proc Natl Acad Sci U S A 77:6715-6719.

Guidelines Subcommittee. 1999. World Health Organization-International Society of Hypertension Guidelines for the Management of Hypertension. Guidelines Subcommittee. J Hypertens 17:151-183.

Havlik, R. J. and Feinleib, M, 1982. Epidemiology and genetics of hypertension. Hypertension 4(5 Pt 2):III121-7. 
Hunt SC, Hasstedt SJ, Kuida H, Stults BM, Hopkins PN, Williams RR, 1989. Genetic heritability and common environmental components of resting and stressed blood pressures, lipids, and body mass index in Utah pedigrees and twins. Am J Epidemiol. 129(3):625-38.

Li R., Liu Y, Li Z, Yang L, Wang S, Guan MX, 2009. Failures in mitochondrial tRNAMet and tRNAGln metabolism caused by the novel A4401G mutation are involved in essential hypertension in a Han Chinese family. Hypertension Aug;54(2):329-37

Li Z, Liu Y, Yang L, Wang S, Guan MX, 2007. Maternally inherited hypertension is associated with the mitochondrial tRNAIle A4295G mutation in a Chinese family. Biochem Biophys Res Commun 367: 906-911.

Liu Y, Li R, Li Z, Wang X, Yang L, Wang S, Guan MX, 2009. The mitochondrial tRNAMet $4435 \mathrm{~A}>\mathrm{G}$ mutation is associated with maternally hypertension in a Chinese pedigree. Hypertension Jun;53(6):1083-90

Liu Y, Li Z, Yang L, Wang S, Guan MX, 2008. The mitochondrial ND13308C mutation in a Chinese family with the secondary hypertension. Biochem Biophys Res Commun 368: 18-22.

Longini IM Jr, Higgins MW, Hinton PC, Moll PP, Keller JB, 1984. Environmental and genetic sources of familial aggregation of blood pressure in Tecumseh, Michigan. Am J Epidemiol. 120(1):131-44.

M.J. Rieder, S.L. Taylor, V.O. Tobe, D.A. Nickerson, 1998. Automating the identification of DNA variations using quality-based fluorescence re-sequencing: analysis of the human mitochondrial genome, Nucleic Acids Res. 26 967-973.

Maniura-Weber, K., Helm, M., Engemann, K., Eckertz, S., Mollers, M., Schauen, M., Hayrapetyan, A., von Kleist-Retzow, J. C., Lightowlers, R. N., Bindoff, L. A., Wiesner, R. J, 2006. Molecular dysfunction associated with the human mitochondrial 3302A $>\mathrm{G}$ mutation in the MTTL1 (mt-tRNALeu(UUR)) gene Nucleic Acids Research . 34 (22): 6404-6415 .

Miller JZ, Weinberger MH, Christian JC, Daugherty SA, 1987. Familial resemblance in the blood pressure response to sodium restriction. Am $\mathrm{J}$ Epidemiol 126:822-830.

Reik W, Walter J, 2001. Genomic imprinting: parental influence on the genome. Nat Rev Genet 2:21-32.

Rice T, Vogler GP, Perusse L, Bouchard C, Rao DC, 1989. Cardiovascular risk 
factors in a French Canadian population: resolution of genetic and familial environmental effects on blood pressure using twins, adoptees, and extensive information on environmental correlates. Genet Epidemiol. 6(5):571-88.

Roe BA, Ma DP, Wilson RK, and Wong JF, 1985. The complete nucleotide sequence of the Xenopus laevis mitochondrial genome. J Biol Chem 260:9759-9774.

Ruiz-Pesini E, and Wallace DC, 2006. Evidence for adaptive selection acting on the tRNA and rRNA genes of human mitochondrial DNA. Hum Mutat 27:1072-1081.

S. Anderson, A.T. Bankier, B.G. Barrell, M.H.L. deBruijn, A.R. Coulson, J. Drouin, I.C. Eperon, D.P. Nierlich, B.A. Rose, F. Sanger, P.H. Schreier, A.J.H. Smith, R. Staden, I. Young, 1981. Sequence and organization of the human mitochondrial genome, Nature 290:457-465.

Wang S, Li R, Fettermann A, Li Z, Qian Y, Liu Y, Wang X, Zhou A, Mo JQ, Yang L, Jiang P, Taschner A, Rossmanith W, Guan MX, 2011. Maternally Inherited Essential Hypertension Is Associated With the Novel 4263A>G Mutation in the Mitochondrial tRNAIle Gene in a Large Han Chinese Family. Circ. Res. $108 ; 862-870$.

Silvestri, G., Santorelli, F. M., Shanske, S., Whitley, C. B., Schimmenti, L. A., Smith, S. A. and DiMauro, S, 1994. "A new mtDNA mutation in the tRNALeu(UUR) gene associated with maternally inherited cardiomyopathy". Human Mutation $3(1): 37-43$.

Spagnolo, M., Tomelleri, G., Vattemi, G., Filosto, M., Rizzuto, N., Tonin, P, 2001. A new mutation in the mitochondrial tRNA(Ala) gene in a patient with ophthalmoplegia and dysphagia Neuromuscular Disorders . 11 (5): 481-484 .

Sun F, Cui J, Gavras H, Schwartz F, 2003. A novel class of tests for the detection of mitochondrial DNA-mutation involvement in diseases. Am J Hum Genet. Jun;72(6):1515-26.

Suzuki T, Nagao A, and Suzuki T, 2011. Human mitochondrial tRNAs: Biogenesis, function, structural aspects, and diseases. Annu Rev Genet 45:299-329.

The sixth report of the Joint National Committee on Prevention, Detection, Evaluation and Treatment of High Blood Pressure, 1997. Arch. Intern. Med. $157: 2413-2446$.

Wallace DC, Lott MT, 2003. MITOMAP: A Human Mitochondrial Genome Database. Available at: http://www.mitomap.org. 
Zinner SH, Levy PS, Kass EH, 1971. Familial aggregation of blood pressure in childhood. N. Engl. J. Med. 284: 401-4. 